\title{
LÉXICO Y SINTAXIS EN LOS DICCIONARIOS MONOLINGÜES DEL ESPAÑOL
}

\author{
Mª Antonia Martínez Linares \\ Dolores Azorín Fernández \\ (Universidad de Alicante)
}

\begin{abstract}
RESUMEN
In this paper we have tried to determine if monolingual Spanish Dictionaries take into account the relationship between Lexis and Syntax as one basis of their approach. We have also tried to establish whether failure to take this relationship into account, in a systematic way, may be a serious obstacle to the achievement of the aims of the Dictionary in question.
\end{abstract}

1. Si la separación metodológica entre léxico y sintaxis fue una constante en los planteamientos lingüísticos del estructuralismo clásico, es evidente que, en la actualidad, la interrelación léxico-sintaxis ocupa un lugar central en la mayoria, por no decir en la totalidad, de los modelos de descripción: Gramática Generativa, Gramática Léxico-Funcional, Gramática Funcional, etc. Todos parecen coincidir en que no se puede mantener la separación de ambos componentes, aunque difieran en el alcance que dan a cada uno y en la forma de conectarlos ${ }^{1}$. Por lo tanto, léxico y sintaxis son la base de la gramática, entendida como descripción y explicación de la estructura de una lengua.

Así, prescindiendo de cualquier formulación teórica específica, se asume, de manera general, que las reglas de la sintaxis no pueden operar sólo con categorías generales del tipo Nombre, Verbo, o con subcategorías, no menos generales, como Verbo transitivo, Ver ${ }^{x} x^{\prime}$ intransitivo, etc. Se precisan, por el contrario, subclases sintáctico-semánticas más específicas, que implican un análisis de las

1 Véase Bresnan, 1982; Dik, 1980; Demonte, 1989; Jackendoff, 1990. 
piezas léxicas cuyo límite, hoy por hoy, sólo parece depender del refinamiento con que se practique la descripción.

En efecto, para formular afirmaciones gramaticales significativas, por ejemplo, sobre la conversión de una oración en construcción pasiva, sobre la selección modal, u otros aspectos de la sintaxis de una lengua, no es suficiente saber si un verbo, pieza clave en la organización oracional, es transitivo o intransitivo; son necesarias informaciones más pormenorizadas tales como: el número de argumentos que selecciona, el papel semántico que les asigna - agente, paciente, etc.—, el tipo de estructura en que se proyecta — sintagma nominal, oración-, y todo ello para cada uno de los sentidos, realmente diferenciados, que esa pieza léxica exhiba.

Consecuentemente, la descripción del léxico, en tanto que parte de la gramática, ha tenido que ir enriqueciéndose, cada vez más, con aspectos de tipo relacional o combinatorio, trandicionalmente considerados dominio de la sintaxis; al tiempo que se ha ido poniendo de relieve que el comportamiento sintáctico de cada pieza léxica no es enteramente idiosincrásico sino predecible, en buena medida, a partir de sus rasgos de significado.

Es, pues, generalmente admitido que el significado de los verbos está en conexión con su estructura argumental. Es decir, con el número de argumentos, de entidades que requiere para formar una predicación completa, con el tipo de entidades -objetos, eventos, animados, inanimados- que selecciona como argumentos y con el papel semántico que les asigna - agente, causa, objeto afectado, destinatario, ubicación, etc.- . De modo que tener en cuenta la estructura argumental es pertinente tanto para describir el significado de un verbo como para, lógiçamente, diferenciar acepciones, ya que cada acepción puede corresponder a, puede proyectarse en, una estructura argumental distinta ${ }^{2}$.

Tomemos por ejemplos los verbos de «influencia», ordenar, mandar, aconsejar, obligar, forzar, etc. Por su significado común, el que permite catalogarlos como tales verbos de «influencia»: «alguien influye en alguien para que realice posteriormente algo», está claro que son verbos que seleccionan tres argumentos, que deben poner en relación tres entidades para formar una predicación completa:

$1^{\circ}$ : La entidad que ejerce su influencia. Puede ser, en sentido estricto, un agente, y como tal, humano, El jefe de la oposición obligó al presidente a presentar la cuestión de confianza. Puede ser también, en algunos casos, una causa, una entidad inanimada: La recesión económica ha obligado a los trabajadores a apretarse el cinturón. Esta primera entidad se realiza, en la diátesis básica, como sujeto.

$2^{\circ}$ : Aquel en quien se influye para que se realice o tenga lugar el proceso. Ha

2 Véase Levin, 1991; Schroten, 1992; Cowie, 1989. 
de ser humano o animado. Su proyección sintáctica es como objeto directo - al presidente, a los trabajadores-, o como objeto indirecto -Ordenó a los diputados de su grupo que votasen en contra-.

$3^{\text {g: }}$ El proceso que se desea que tenga lugar. Este argumento corresponde a una entidad abstracta, un proceso, una acción, un evento; de ahí que se realice mediante una oración sustantiva o una nominalización, y no mediante un sintagma nominal que tenga como referente un objeto físico:

Ordenó a los diputados de su grupo que votasen en contra

El general Villa ordenó a sus incondicionales el asalto al carro blindado

Lo forzó a dimitir

Las obligó a la reconciliación

Pero no:

* Los obligó a un libro

* Los forzó a la tortilla de patatas

Si esa es la estructura que se relaciona con su significado en tanto que verbos de «influencia», es lógico que los cambios en la estructura argumental estén en correlación con cambios de significado:

El ladrón forzó la cerradura

Carlos Alberto ordenó la mesa

Está claro que ya no estamos ante verbos de influencia, sino ante verbos de «acción afectadora» (Cano Aguilar, 1981: 145; Moreno Cabrera, 1991: 350). Aluden a una actividad controlada por un agente que se ejerce sobre un objeto físico preexistente. Requiere sólo dos argumentos, no tres; es decir, relaciona dos entidades: la que realiza la actividad y el objeto sobre el que se ejerce la misma. Estas dos entidades son, además, de índole distinta a las implicadas en el sentido anterior:

$1^{\circ}$ : Un agente humano o animado el ladrón, Carlos Alberto-que, en la diátesis básica, se proyecta como sujeto.

2: El objeto afectado - la cerradura, la mesa-. Dado que no es una acción o un proceso, no se realiza mediante una oración o una nominalización, sino mediante un sintagma nominal que tiene como referente un objeto, posibilidad esta que, como hemos señalado, no sería aceptable en la acepción anterior.

Consideremos ahora los siguientes enunciados:

El dependiente mandó el paquete a Madrid

El mayordomo dejó al niño en el colegio 
Tampoco manifiestan ya la estructura argumental típica de los verbos de «influencia», ni pueden interpretarse como tales. Son verbos de «acción afectadora» que implica desplazamiento (Cano Aguilar, 1981: 144). Precisan también tres argumentos, pero de tipo distinto:

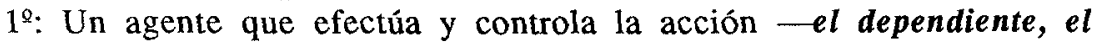
mayordomo-.

$2^{\circ}$ : El objeto físico sobre el que se ejerce la acción, es decir, el que resulta afectado por ella. No puede, por tanto, realizarse mediante una oración, sino como un sintagma nominal el paquete, el niño-.

$3^{\circ}$ El lugar hacia el que se efectúa el desplazamiento. Se corresponde, lógicamente, con un complemento locativo -a Madrid, en el colegio-.

Parece claro, pues, que cada acepción se relaciona con una estructura sintáctico-semántica diferente, con un comportamiento gramatical distinto. Si admitimos que esto es así, podemos preguntarnos qué interés puede tener el asumir esa conexión léxico-sintaxis desde el punto de vista de la práctica lexicográfica.

De todos es sabido que los objetivos que se persiguen al elaborar un diccionario son muy distintos de los que pueda plantearse un linguiista que pretenda describir el léxico de una lengua, ya lo aborde como un dominio independiente, ya lo integre como parte de la descripción gramatical (Bosque, 1989: 73-74).

El diccionario de la lengua es una obra esencialmente práctica, con una orientación didáctica clara, que tiene como destinatario a un usuario medio, sin conocimientos lingüísticos pero competente en su lengua. Su objetivo debe encaminarse a atender las necesidades de ese usuario (Dubois y Dubois, 1971:4956). Por ello él diccionario debe y puede prescindir de informaciones que no sean asequibles o necesarias para satisfacer las demandas de quienes lo consultan habitualmente. No pretende ofrecer una descripción sistemática, de acuerdo con un modelo lingüístico teórico, sino ser claro y, ante todo, útil. Como, además, el hablante nativo, competente en su lengua «llena intuitivamente los vacíos que el mensaje lexicográfico presenta» (Seco, 1979: 191), el diccionario puede dejar mucha información implícita, algo que sería inaceptable para un lingüista que pretenda hacer de su trabajo una tarea científica (Levin, 1991: 206).

Por su parte, la descripción del léxico es una labor específicamente lingüística, dependiente de una cierta concepción del funcionamiento del lenguaje, que tiene como objetivo una descripsión sistemática y explícita. No se encamina a una finalidad prácticạ ni tiene como destinatario a un lector medio, sin conocimientos teóricos. Es obvio, pues, que un diccionario común de lengua no tiene que, y no debe, incorporar miméticamente los complejos procedimientos de descripción propios de un enfoque exclusivamente lingüístico. De ahí que 
sea, hasta cierto punto, legítimo y comprensible que la confección de obras lexicográficas haya discurrido en buena parte alejada de las innovaciones introducidas en el campo de la lingüística teórica (Alvar, 1993:88).

Pero, pese a las diferencias que separan la aproximación científica al estudio del léxico de la más práctica o utilitaria del diccionario, no hay que olvidar que el lexicógrafo que elabora un diccionario y el lingüista que describe el léxico comparten un objetivo común: ambos se encaminan a explicitar el significado de las piezas léxicas, a diferenciar las acepciones ${ }^{3}$ verdaderamente relevantes.

Por ello, a pesar de las dificultades prácticas que representa para el lexicógrafo, y a pesar de los numerosos problemas no resueltos por la teoría linguística -en relación sobre todo con los papeles temáticos ${ }^{4}$, son cada vez más los investigadores que subrayan la necesidad de que en la elaboración de las obras lexicográficas se tenga en cuenta esa interrelación léxico-sintaxis que, en el ámbito de la lingüística teórica, se acepta como algo indiscutible ${ }^{5}$.

Fijémonos, por ejemplo, en que si aceptamos que existe una relación entre el significado de un verbo, su clase semántica, los argumentos que selecciona y sus propiedades sintácticas -el que seleccione una oración en indicativo o en subjuntivo, el que exija como objeto un sintagma nominal o una oracióndebemos aceptar, asimismo, que los entornos sintácticos en sí, en cuanto que ponen de relieve distintas propiedades semánticas, pueden diferenciar las acepciones de un verbo y, por tanto, pueden ser necesarios para delimitar y establecer las acepciones mismas; para clarificarlas al usuario. Tareas estas elementales y básicas para un diccionario monolingüe.

De manera que si no podemos pedirle a un diccionario que haga explícitas, de un modo técnico, las propiedades sintácticas de las distintas acepciones ${ }^{6}$, sí deberíamos analizar si factores como estos son tenidos en cuenta, pongamos por caso, a la hora de conformar los enunciados definitorios, o de seleccionar los ejemplos adecuados para cada acepción. O si, por el contrario, la información que, directa o indirectamente (Ahumada Lara, 1988; Bosque, 1982), proporcionan sobre los entornos sintáctico-semánticos es insuficiente con miras a llevar a

3 El concepto de acepción sigue siendo uno de los puntos problemáticos y aún no resueltos de la lexicografía, tanto teórica como práctica. Pero no es objetivo de este trabajo polemizar sobre el tema. De modo que en el transcurso del mismo, utilizaremos el término 'acepción' en su sentido más comunmente extendido y aproblemático: Cada uno de los diferentes sentidos, reconocidos y aceptados por el uso, que se asocian a una pieza léxica (Hzmández, 1991: 133).

4 Véase, a este propósito, Jackendoff, 1990; Gràcia i Solé, 1989, pp. 127 y sigs.

5 Por mencionar algunos trabajos recientes: Vilela, 1992; Calderón, 1994; Cowis, 1989; Schroten, 1992; Gross, 1981; Garrido Medina, 1992; Busch, 1992; Shack Rasmussen, 1992.

6 Tarea esta propia de los diccionarios de orientación sintáctica, como los de valencias, o los de construcción y régimen (Báez, 1988: 41:92). 
término esas tareas que hemos calificado antes como elementales y básicas para un diccionario.

En lo que sigue, trataremos de proyectar esa pregunta sobre una muestra del DRAE y del DGILE? ${ }^{7}$ en la que hemos procurado, con el fin de paliar lo exiguo de la misma, incluir distintas clases sintáctico-semánticas de verbos ${ }^{8}$. Debe entenderse que los casos que analizamos no pretenden ser, en modo alguno, representativos del tratamiento que ambos diccionarios otorgan al conjunto de sus entradas verbales. Tan sólo se trata de ejemplos donde, singularmente, se hace patente la necesidad de integrar la información sobre los entornos sintácticosemánticos en la descripción del significado; cosa que, por otro lado, llevan a cabo tanto el DRAE como el DGILE con bastante frecuencia, aunque no de manera regular'.

2. Es un hecho comúnmente aceptado que el hablante que utiliza el diccionario monolingüe de su propia lengua lo hace, preferentemente, para entender el significado de una unidad léxica que ha encontrado situada en un determinado contexto, actividad para la que, como subraya I. Bosque (1982: 118): «Es necesaria una cantidad de información mucho menor que la que se precisa para usar con propiedad dicha unidad».

Pero aunque esta actividad requiera menos información, cabe preguntarse si la que efectivamente proporcionan nuestros diccionarios sobre la estructura sintáctico-semántica de los verbos es o no suficiente para que se cumpla, al menos, esa función decodificadora básica; es decir, para «reconocer, identificar o sencillamente entender el significado de una unidad léxica» (Bosque, 1982: 118).

Como ya han puesto de relieve estudios recientes sobre esta cuestión (Schroten,

7 Diccionario de la lengua española, Real Academia Española, MMadrid, Espasa-Calpe, 1992. En adelante, DRAE.

Diccionario general ilustrado de la lengua española, (nueva redacción dirigida por M. Alvar Ezquerra), Barcelona, Biblograf, 1987. En adelante, DGILE.

8 Hemos elegido estos dos diccionarios, como fuente de nuestros ejemplos, por tratarse de obras de similar extensión, ampliamente conocidos y utilizados por el usuario medio y de reconocido prestigio.

9 Ahumada Lara (1988) ha puesto de relieve cómo nuestros diccionarios generales más representantivos, el DRAE, el DGILE y el DUE (Diccionario de uso del español, María Moliner), tienen en cuenta las características sintácticas o combinatorias de las piezas léxicas, especialmente cuando se trata de verbos, aunque éstas no se describan explícitamente. La información sobre el régimen, el tipo de complementación, la naturaleza semántica de los complementos, etc., puede deducirse, en la mayoría de las ocasiones, de la conformación sintáctica del enunciado definitorio. «...la información sintáctica implícita es aquella que interpretamos cuando la estructura de la definición coincide, total o parcialmente, con la que, total o parcialmente, puede proyectar el definido.» (Ahumada Lara, 1988:86). El ejemplo es otra vía indirecta de proporcionar información sobre los entornos sintácticos (Alvar Ezquerra, 1993: 132-136). Este procedimiento es, efectivamente, utilizado por nuestros diccionarios, en particular por el DGILE, aunque tampoco de manera regular (Ahumada Lara, 1989:82). 
1992; Vilela, 1992; Gross, 1981; Garrido Medina, 1992; Cowie, 1989) este objetivo en muchos casos no llega a cumplirse por no estar diferenciados adecuadamente los entornos sintáctico-semánticos.

Veamos, por ejemplo, los significados básicos que corresponden a los verbos medir y presentar (Cano Aguilar, 1981: 322; Moreno Cabrera, 1991: 345), atendiendo a la estructura en que se integran, y veamos, a continuación, qué tratamiento da el DGILE a estas unidades.

Ambos verbos tienen en común el poder formar parte de dos esquemas oracionales distintos, que se relacionan con sentidos diferentes:

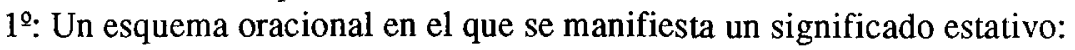

El niño medía l'45

La cama medía $2 X 2$

El niño presentaba sintomas de desnutrición

El jardín aún presentaba huellas de su antiguo esplendor

El significado oracional que subyace a estos enunciados puede parafrasearse de la siguiente manera: «una entidad - el niño, la cama, el jardin - se halla en un determinado estado, exhibe cierta característica o propiedad». Para formar una predicación completa con este sentido, ambos verbos precisan dos argumentos: uno -el que se realiza como sujeto- corresponde a la entidad animada o inanimada que se halla en un estado o tiene una propiedad. Otro que alude a la propiedad, característica o circunstancia relativa al estado (Moreno Cabrera, 1991: 345).

$2^{\text {o: }}$ Un esquema oracional con significado de acción afectadora:

El dependiente midió la cama

Cuca Ribera presentó la colección otoño-invierno

El sentido genérico de este esquema viene a ser: «alguien —entidad típicamente humana - realiza una actividad controlada que se ejerce sobre otra entidad, animada o inanimada».

Con este significado, medir y presentar requieren también dos argumentos, pero de un tipo diferente. Así el correspondiente al sujeto es, como hemos señalado, una entidad típicamente humana, ya que ambos verbos aluden aquí a una «actividad controlada».

Supongamos que un hablante español tuviera la necesidad de consultar cuál es el significado de medir y presentar en enunciados como los que anteriormente hemos relacionado con el sentido «activo»:

El dependiente midió la cama

Cuca Ribera presentó la colección otoño-invierno 
Si acude al DGILE, encontrará, en los artículos correspondientes, las siguientes acepciones:

medir. tr. Determinar la longitud, extensión, volumen o capacidad [de una cosa]; - a palmos, por varas; - una cosa con otra; - por, o con, un rasero. 2. Examinar [si los versos tienen la medida correspondiente a los de su clase]. 3. Comparar [una actividad, aptitud, etc.] con otra:-las fuerzas; -el ingenio. 4. tr. prnl. Moderarse en decidir o ejecutar [una cosa] ajustándose a sus facultades: medirse uno consigo mismo; medirse con sus fuerzas, en las palabras. 5. Reñir, pelearse ${ }^{10}$.

presentar. tr. Poner [una cosa] en la presencia de uno; mostrarla: presentar un grabado; el coche se presentó con mal aspecto; presentarse por el lado favorable. 2. p. anal. Regalar (dar). 3. Proponer [a un sujeto] para una dignidad, oficio o beneficio eclesiástico: -de, por, candidato. 4. Introducir [a uno] en la casa o en el trato de otro, a veces recomendándole personalmente: —en la corte. 5. Prnl. Comparecer en algún lugar o acto. 6. Esp. Comparecer ante un jefe o autoridad: presentarse al general. 7 . Ofrecerse voluntariamente para un fin. 8. DER. Comparecer en juicio.

Aunque ni las definiciones ni los ejemplos acoten claramente qué tipo de sujeto pueden llevar ambos verbos, en cualquiera de sus acepciones, la información que proporciona el diccionario podría ser suficiente para que el hablante relacione el significado de medir y presentar en los enunciados anteriores con las acepciones que, en sus respectivos artículos, aparecen en primer lugar, correspondientes ambas a esquemas de acción:

El dependiente determinó la extensión de la cama

Cuca Ribera puso su colección en la presencia de alguien; la mostró

Pero si las dudas del hablante procediesen de los enunciados que hemos clasificado como estativos:

El niño presentaba sintomas de desnutrición

La cama medía $2 X 2$

El jardín aún presentaba huellas de su antiguo esplendor

la información aportada por el diccionario no sería suficiente para resolverlas. El ser un hablante competente en su lengua y su conocimiento del mundo le harían desechar una interpretación «agentiva» de la cama, de el jardín, o de el

10 Utilizamos los dos guiones en sustitución de la línea quebrada que, en este diccionario, se utiliza como símbolo de repetición del lema. 
niño: no se entiende que ejerzan una actividad controlada sobre algo. Pero ni el significado estativo que tienen aquí ambos verbos, ni, consecuentemente, el hecho de que, como tales, puedan llevar sujetos inanimados, son aspectos que queden recogidos en los artículos del diccionario ${ }^{11}$.

Consideremos ahora otro tipo de verbos como, por ejemplo, aumentar y mejorar. Según la tipología de Cano Aguilar (1981: 229-239), estos verbos se caracterizan por admitir dos tipos de estructuras sintáctico-semánticas, relacionadas, lógicamente, con dos sentidos oracionales distintos:

$1^{\circ}$ : Una estructura transitiva, de sentido causativo o agentivo: «alguien o algo - entidad que se presenta como sujeto - hace que se desarrolle un proceso que afecta a otra entidad - la que se realiza como objeto directo-»:

La crisis de los cuarenta aumentó su inestabilidad emocional

La cotización en Bolsa mejoró las perspectivas de crecimiento de la empresa

2:- Una estructura intransitiva, de sentido anticausativo: «un proceso se desarrolla en, afecta a, una entidad - la que se presenta como sujeto de la oración-», sin que se destaque como argumento nuclear la entidad que da origen a ese proceso:

El precio de la gasolina aumentó en el último trimestre Su situación familiar ha mejorado

El DRAE y el DGILE proporcionan las siguientes acepciones para aumentar:

DRAE: aumentar. tr. Acrecentar, dar mayor extensión, número o materia a alguna cosa. ú.t.c. intr. y c. prnl. 2. Adelantar o mejorar en conveniencias, empleos o riquezas. ú.t.c. pml.

DGILE: aumentar. tr. Dar mayor extensión, número o materia [a una cosa]: -el sueldo a los empleados; el precio de las subsistencias aumenta. 2. Adelantar o mejorar en conveniencias, empleos o riquezas.

Dada la información que ambos suministran, el hablante podría identificar con la primera acepción el sentido de aumentar en La crisis de los cuarenta

1 El DRAE, por su parte, sí que recoge las acepciones estativas:

s.v. medir. 4. intr. Tener determinada dimensión, ser de determinada altura, longitud, superficie, volumen, etc. Juan MIDE un metro setenta de altura. La finca MIDE cuatro mil metros cuadrados.

s.v. presentar. 4. Tener ciertas características o apariencias: La operación PRESENTA ciertas dificultades; Desde ayer el enfermo PRESENTA una notable mejoría. 
aumentó su inestabilidad emocional, la construcción de sentido causativo. Sin embargo, para el sentido anticausativo que manifiesta el enunciado El precio de la gasolina aumentó en el último trimestre, el DRAE solamente apunta, por medio de abreviaturas, la posibilidad del empleo intransitivo de aumentar: ú.t.c. intr. El DGILE, por su parte, ofrece un tratamiento también incompleto de esta pieza léxica, ya que en la primera acepción solamente se define el sentido causativo, el que debe realizarse mediante una construcción transitiva, sin mencionar siquiera la posibilidad de empleo intransitivo. No obstante, de los dos ejemplos que acompañan a tal definición, sólo uno resultaría adecuado, puesto que en El precio de las subsistencias aumenta no puede entenderse que «el precio de las subsistencias dé mayor extensión a una cosa». El sentido que tiene aumentar en este ejemplo sería el anticausativo: «algo —el precio de las subsistencias- experimenta un aumento».

El tratamiento en ambos casos es, pues, deficiente en lo que respecta a la explicitación del sentido anticausativo; aunque, al menos, en el DGILE la inclusión de ejemplos de los dos tipos de estructuras es más orientativa para el usuario que la mera indicación del cambio de subcategoría -ú.t.c. intr.- que aporta el DRAE.

En el caso de mejorar ocurre algo similar. Ambos diccionarios recogen las siguientes acepciones:

DRAE: mejorar. tr. Adelantar, acrecentar una cosa, haciéndola pasar a un estado mejor. 2. Poner mejor, hacer recobrar la salud perdida. 3. Aumentar cada licitador el precio puesto a una cosa que se ofrece en venta, subasta, etc. 4. Der. Dejar en el testamento mejora a uno o varios de los herederos. 5 . intr. Ir recobrando la salud perdida; restablecerse. ú.t.c. prnl. 6. Ponerse el tiempo más favorable o benigno. ú.t.c. prnl. 7. Ponerse en lugar o grado ventajoso respecto del que antes se tenía. ú.t.c. prnl.

DGILE: mejorar. tr. Hacer pasar [una cosa] de un estado a otro mejor. 2. Pujar II. 3. DER. Dejar en el testamento mejora [a los hijos o nietos]: - a una hija en tercio y quinto. 4. intr. prnl. Restablecerse o aliviarse el enfermo. 5. Ponerse el tiempo más benigno. 6. Medrar uno en su posición social o económica:-de condición. 7. Mejorando lo presente, expr. de cortesía cuando se alaba a una persona ausente.

Tal vez el hablante podria identificar el sentido que tiene mejorar en Su imagen pública ha mejorado sensiblemente o en Su situación familiar ha mejorado con la acepción 7 del DRAE, pese a que la ausencia de ejemplos no permite discernir qué tipo de entidades son las que "se ponen en lugar o grado ventajoso respecto del que antes tenían'. Pero si consulta el DGILE, difícilmente el usuario podría identificar el sentido de mejorar en esos enunciados anticausativos, ya que ni su imagen pública ni su situación familiar son 'enfermos' o 'fenómenos meteorológicos', únicas entidades que en este diccionario se mencionan como 
posibles sujetos de las construcciones anticausativas recogidas en 4 y 5 que, curiosamente, aparecen como acepciones distintas. Hubiera sido más informativo reunir en una sola acepción este sentido anticausativo: «alguien o algo experimenta una mejora", concretando en los ejemplos qué tipo de entidades aparecen más comúnmente en esta clase de construcción: El tiempo/ el enfermo/ la situación ... mejora.

Algo similar ocurre con el significado del verbo tranquilizar, en su uso pronominal, si este se pretende deducir de la información que de él proporcionan el DRAE y el DGILE:

DRAE: tranquilizar. tr. Poner tranquila, sosegar, a una persona o cosa. ú.t.c. prnl.

DGILE: tranquilizar.tr.-prnl. Hacer desaparecer la agitación, la inquietud [a una persona o cosa].

En ambos casos, la definición solamente recoge uno de los posibles entornos sintácticos, el transitivo, en que puede aparecer esta unidad. Pero ¿cómo deducc el usuario su significado en Finalmente, las aguas se tranquilizaron al cesar el fuerte viento, si no es por su propio conocimiento idiomático? La información ú.t.c. prnl. no es suficiente para interpretar el significado de esta construcción anticausativa, en la que el sujeto es la entidad que «resulta tranquilizada» no la que "pone tranquila».

Cabría preguntarse si la falta de datos sobre el empleo pronominal obedece a que el lexicógrafo considera que este tipo de información es competencia estricta de la gramática, dominio de las regularidades sistemáticas que el hablante nativo intuitivamente conoce. Pero, al margen de que la regularidad de las construcciones pronominales es, cuando menos discutible ${ }^{12}$, lo cierto es que,

12 Véase, por ejemplo, Vera Luján (1990), Martín Zorraquino (1979).

13 Véanse, por ejemplo, los artículos que el DRAE y el DGILE dedican a los verbos indisponer y hundir:

DGILE: s.v. indisponer. 3. Causar indisposición, experimentarla: El calor me indispone; se ha indispuesto.

s.v. hundir. tr.-prnl. Sumir, meter en lo hondo [alguna cosa]: -en el cieno. 5. prnl. Arruinarse un edificio, sumergirse una cosa: hundirse en el agua.

DRAE: s.v. indisponer. 3. Causar indisposición o falta leve y pasajera de salud. 4. Prnl. Experimentarla.

s.v. hundir. tr. sumir, meter en lo hondo. 6. pml. Arruinarse un edificio, sumergirse en lo hondo.

Nótese que los significados y los ejemplos de la acepción 3 de indisponer tal como los recoge el DGILE corresponden uno a la construcción transitiva - causar indisposición, El calor me indispone-, otro a la construcción pronominal: experimentarla, se ha indispuesto. 
en otros casos similares, estos diccionarios sí diferencian el significado pronominal $^{13}$.

Para concluir con esta sucinta muestra, veamos un verbo más, estimar, que también cambia de significado según el esquema sintáctico-semántico en el que se incluya. Según el tipo de complementación que lleve, puede entenderse como verbo de juicio, sinónimo de juzgar - Estimo que tu presencia es innecesariao como equivalente de tener aprecio: Estimo mucho a mis amigos.

Si un hablante acudiera al DRAE para clarificar el sentido que tiene estimar en un enunciado como Los del pueblo siempre han estimado al cacique Don Fulgencio, encontraría las siguientes acepciones:

tr. Apreciar, poner precio, evaluar las cosas. 2. Juzgar, creer. 3. Hacer aprecio y estimación de una persona o cosa. ú.t.c. prnl.

Con esta información el hablante no podría averiguar, salvo que ya lo sepa y sólo busque confirmación, con qué acepción se relaciona estimar en ese enunciado, si con la 2 o con la 3: Los del pueblo siempre han juzgado al cacique Don Fulgencio, Los del pueblo siempre han hecho aprecio y estimación del cacique Don Fulgencio. Tampoco la consulta de juzgar y creer, utilizados como definidores en la acepción 2 contribuirá a aclararlo, dado que sus respectivos artículos adolecen de un mismo defecto: la ausencia de ejemplos que ilustren sobre el tipo de complementación que corresponde a estos sentidos. Ese problema se hubiera evitado reflejando, bien a través de ejemplos, bien con una información explícita que, cuando estimar es equivalente a juzgar o creer, no lleva como complemento un s.ntagma nominal alusivo a un objeto o a una persona, sino una oración, ya plena, Los del pueblo estiman que Don Fulgencio es un cacique, ya reducida, Los del pueblo estiman necesario un adelanto de las elecciones.

Por tanto, estimar en el enunciado propuesto, con un complemento humano, sólo podría entenderse según la tercera acepción: «hacer aprecio y estimación de una persona o cosa» ${ }^{14}$.

3. Como hemos podido comprobar en todos los verbos que hemos comentado anteriormente, la no diferenciación de sus distintas estructuras sintácticosemánticas dificulta $o$, en algunos casos, impide que el diccionario lleve a término su función básica: la decodificación. Ciertamente, son demasiados los aspectos, relevantes desde el punto de vista de la significación, que no se explicitan, suponemos que porque se confian a la competencia de los hablantes.

Pero no olvidemos que, por un lado, los diccionarios monolingües también son objeto de consulta por parte de hablantes no nativos que ya han adquirido un

14 Tanto el DUE de María Moliner, como el DGILE sí incluyen ejemplos ilustrativos de los complementos posibles en cada uno de estos sentidos. 
cierto dominio del idioma, a los que no basta la simple transcodificación que ofrecen los diccionarios bilingües al uso, sino que prefieren definiciones en contexto (Hartman, 1987; Rey-Debove, 1971: 40).

Para estos, en general, las definiciones de los diccionarios monolingües resultan insatisfactorias. En parte, porque no pueden llenar con su competencia las lagunas informativas que pasan inadvertidas a un hablante nativo. En parte, porque, para ellos, no es la decoficiación la única meta, sino también la reutilización o producción.

Por otro lado, ceñirse sólo a una finalidad decodificadora supone una infrautilización de la obra lexicográfica, ya que, como sugiere Calderón Campos (1994), el diccionario debería servir no sólo para entender palabras, sino también para aprender a usarlas. Pero, para esa función codificadora, tal como afirma Bosque (1982: 118), la información necesaria «es mucho más específica y suele aparecer en el diccionario de manera irregular».

Para este fin, efectivamente, es imprescindible que el diccionario, en el caso de los verbos, especifique, para cada acepción, si puede construirse con un sujeto indeterminado ${ }^{15}$, si, por el contrario, este debe ser humano, o inanimado; qué tipo de objetos selecciona; en definitiva, qué argumentos precisa y a través de qué estructuras se realizan. Pero, como puede deducirse de los ejemplos analizados, no parece que nuestros diccionarios se planteen, como punto de partida, la necesidad de reflejar, de manera sistemática, los aspectos antes mencionados. De ahí que no siempre sean el útil más apropiado para que el usuario pueda resolver sus dudas acerca de la corrección del enunciado que se propone construir.

Por jemplo, volviendo a estimar, el último de los verbos que hemos comentado, a partir de los datos suministrados por el diccionario, no podría determinarse si Estimo que seas agradecido es un enunciado correcto, o si quiere decir lo mismo que Estimo que eres agradecido.

Quizá las dificultades que esa falta de información entraña no puedan calibrarse en su justa dimensión ni en el caso de estimar ni en el de los restantes verbos hasta aquí comentados, por tratarse de piezas léxicas escasamente problemáticas para un hablante nativo medio, si bien, como hemos apuntado, no es este el único destinatario de la obra lexicográfica.

Por ello, puede ser más revelador analizar las repercusiones del problema que venimos planteando a partir de verbos, o de acepciones de verbos, en los que, por ser de uso menos frecuente, la competencia del hablante no puede suplir, como en otros casos, las lagunas informativas del diccionario.

Pueden servirnos a este propósito algunas acepciones poco usuales de los verbos indisponer y abrevar.

15 Utilizamos 'sujeto indeterminado' con el sentido que le da Gross (1981): un sujeto no restringido a una determinada clase semántica. 
Desde nuestro punto de vista, en las acepciones que más adelante incluiremos, ni los enunciados definitorios ni el resto de las informaciones complementarias proporcionan pautas suficientes para posibilitar su uso y, en algún caso, ni aún para comprender su significado.

No obstante, para corroborar nuestra apreciación inicial, solicitamos a un grupo de diecisiete alumnos de cuarto de Filología Hispánica que construyesen, a partir de la información dada por los diccionarios, un enunciado no ambiguo para cada una de las acepciones que previamente les habíamos presentado ${ }^{16}$.

En el caso de indisponer, el DRAE y el DGILE dan, como primera acepción, la siguiente:

DRAE: tr. Privar de la disposición conveniente o quitar la preparación necesaria para una cosa. ú.t.c. prnl.

DGILE: tr. Privar [una cosa] de la disposición conveniente para algún fin: -un proyecto de viaje.

En ninguna de las dos se especifica la naturaleza del sujeto - si puede ser un agente humano, una causa, «alguien» o «algo», o ambas cosas-. El ejemplo que proporciona el DGILE es una frase en infinitivo, con un sintagma nominal pospuesto que, suponemos, será el objeto; aunque si se hubiera tratado del sujeto ocuparía la misma posición. En definitiva, el ejemplo no sirve para aclarar con qué clase de sujeto se construye indisponer.

Tampoco se acota claramente el tipo de objeto, si puede ser humano, si debe ser inanimado, si puede ser un objeto físico, un evento, etc. El elemento [cosa] que el DGILE delimita como parte del contorno no es, asimismo, lo bastante explicito al respecto.

En cuanto a la formulación del enunciado definitorio en sí mismo y al ejemplo propuesto por el DGILE para ilustrarlo - indisponer un proyecto de viaje - de aplicarse la prueba de la conmutación (Seco, 1978), el enunciado resultante sería, cuando menos, ambiguo: privar un proyecto de viaje de la disposición conveniente para algún fin.

Por tanto, ni la definición ni, en su caso, el ejemplo, son suficientes para clarificar el sentido o para proporcionar una pauta de uso.

Con la información obtenida de ambos diccionarios, la mayoría de nuestros alumnos construyeron enunciados que respondían al esquema general «alguien —un sujeto humano- INDISPONE un evento -objeto directo-», si bien no quedaba plenamente delimitado qué sentido concreto otorgaban a indisponer. La

16 La propuesta que se hizo a este grupo de alumnos abarcaba, en realidad, un corpus más amplio de acepciones no usuales de verbos. Los dos que comentamos en el presente trabajo son sólo una muestra ilustrativa del problema que nos ocupa. 
ausencia de complementaciones orientativas dejaba abierta la posibilidad de varias interpretaciones. Veamos algunos de esos enunciados:

\section{La profesora indispuso la conferencia \\ El presidente de mesa indispuso la votación \\ Antonio indispuso su partida de cartas \\ El Decano indispuso el comienzo de curso por la falta de profesores}

Sólo un alumno, de los diecisiete ${ }^{17}$, compuso un enunciado que se correspondía con un esquema «alguien INDISPONE un objeto físico»: Voy a indisponer el coche hasta que lo reparen, cuando, de hecho, de la definición del DGILE se debería deducir que lo 'indispuesto' es una «cosa» y no un «evento»o «acontecimiento». De todo ello se colige que la interpretación que mayoritariamente realizaron los alumnos vendría inducida más por el ejemplo que proporciona el DGILE - indisponer un proyecto de viaje- que por la definición en sí. De ahí que, al igual que sucedía con el ejemplo, de aplicarse a los enunciados de los alumnos la prueba de la conmutación, obtengamos frases poco comprensibles: La profesoral el presidente de mesal Antonio/ El Decano priva la conferencial la votación/ su partida de cartas/ el comienzo del cursol de la disposición conveniente para algún fin.

Además, aunque, como hemos indicado, no puede deducirse de estos enunciados qué sentido concreto daban los alumnos a indisponer, parece que el que más fácilmente puede inferirse es «alguien retrasa/ suspende un acto o evento», sentido este que no se corresponde con la definición ${ }^{18}$.

En el caso de abrevar, las dificultades provienen, sobre todo, de la interpretación de las acepciones figuradas que incluyen tanto el DRAE como el DGILE. En el primero de ellos:

4. Saciar. ú.t. en sent. fig. Abrevar el ánimo. 5 prnl. Beber. ú.t.c. intr. y m. en sent. fig.

\section{En el DGILE:}

3. fig. Saciar. 4. fig. Beber: prnl. abrevarse en sangre un tirano.

17 En otro caso aislado, un elumno empleo este verbo con el sentido más habitual de indisponerse: ponerse indispuesto, enfermo; sentido este que se recoge en los diccionarios en una acepción distinta de la que les propusimos.

${ }_{18}$ Los ejemplos que proporciona el Diccionario de Autoridades son, al menos, más esclarecedores para interpretar el significado de esta acepción en particular: Entibia la voluntad con presuntuosas confianzas y la indispone para el uso de las virtudes. 
Puede comprobarse que ninguno de los dos diccionarios señala estas acepciones como desusadas o con cualquier otra marca que acote el nivel de uso. Debe inferirse, por tanto, que se presentan como usos actuales de este verbo en lengua culta común. No obstante, el hecho de que Maria Moliner, en su DUE, no los recoja puede hacer dudar de su plena vigencia.

De cualquier manera, vamos a analizar cómo presentan ambos estas acepciones desde el punto de vista que nos interesa: la acotación de su entorno sintácticosemántico.

Para la acepción 'saciar', el DGILE no ofrece más que una definición sinonímica (Werner, 1982: 276-279) y la marca fig., sin ejemplificación alguna. No especifica qué tipo de complementos puede o debe llevar. El DRAE, por su parte, además de la definición sinonímica, ofrece un ejemplo, abrevar el ánimo, que corresponde al uso figurado, pero tampoco informa sobre los complementos que admite o precisa en su uso recto. Ni uno ni otro indican además la posibilida o necesidad de que lleven un determinado tipo de complementación preposicional de algol con algo, que explicite 'de qué' o 'con qué' 'se abrevan'.

En lo que respecta a la acepción 'beber', resuelta también a través de una definición sinonímica, encontramos las mismas carencias que en el caso anterior. Se indica que es transitivo, pero no sabemos con qué complementos se construye en su uso recto, posible según el DRAE, ni tampoco en sentido figurado. Falta, además, especificar si en ese uso recto el sujeto debe ser 'persona' o sólo 'animal'19. Queda también por explicitar si el uso intransitivo requiere algún tipo de complementación preposicional. El ejemplo que el DGILE aporta, abrevarse en sangre un tirano, parece sugerir que puede llevarlo, pero no clarifica si es o no un complemento obligatorio ${ }^{20}$.

Por tanto, si un hablante quisiera, siguiendo las directrices del diccionario, emplear abrevar, abrevarse como sinónimos de beber o saciar, ya en sentido recto, ya en sentido figurado, podría llegar a construir enunciados como algunos de los propuestos por nuestros alumnos:

Mi abuela me abrevó de pasteles el día de mi santo

Todas las tardes abrevaba a sus hijos de Nocilla

Yo siempre me abrevo antes de trabajar

Me abrevé un litro de Coca-cola

Siempre que venimos a este restaurante nos abrevamos demasiado

Los grandes comilones se abrevan en todas las demostraciones gastronómicas

19 Véase DUE.

20 En la acepción reflexiva que trae Cuervo (1886-1893) se especifica, sin lugar a dudas, que debe llevar un complemento preposicional introducido por en. 
Si tienes sed puedes abrevarte en la cocina

Los futbolistas se abrevan después de cada partido

Ninguno de estos enunciados, sin embargo, respondería a los esquema sintáctico-semánticos que señala Cuervo en el artículo que dedica en su diccionario al verbo abrevar ${ }^{21}$. En ningún caso se deja ver la posibilidad de que abrevar pueda llevar una complementación alusiva a un objeto comestible, o que se pueda utilizar en sentido absoluto, sin régimen que especifique qué se bebe o de qué o con qué se sacia:

abrevar. a) Dar de beber; dícese del ganado (trans.). Refl. Apagar la sed, beber, con en. b) Aplicado a personas. a) En sentido material. Con con para expresar la clase de bebida. «¿Cómo es amargado con hiel el que nos dio el pan de los cielos, y abrevado con vinagre el que nos dio el cáliz de la salud?». b) Met. con de, a semejanza de hartar. «Su mano nos salva del crudo enemigo/ que quiso abrevarnos de llano y de hiel $\aleph^{22}$.

Es evidente, pues, que la información que proporcionan tanto el DRAE como el DGILE, en los ejemplos que hemos examinado, no basta para que el usuario pueda ratificar la corrección de los enunciados que construye.

4. Tanto desde nuestra experiencia de usuarios, como desde el punto de vista de la crítica lexicográfica, se puede afirmar que el diccionario monolingüe cumple, en términos generales, el objetivo que parece básico para el usuario: ayudar a entender el significado de las unidades léxicas, aun en el caso de que no parezca recoger entre sus planteamientos iniciales la necesidad de delimitar, de manera sistemática, los entornos sintáctico-semánticos de estas unidades.

No obstante, en las páginas precedentes, hemos tratado no sólo de evidenciar la importancia de asumir la interrelación léxico-sintaxis en el tratamiento de los verbos, sino también de mostrar cómo la falta de sistematicidad al respecto puede dar lugar a insuficiencias en casos concretos.

Sería, pues, deseable, que los diccionarios fueran más sensibles a la necesidad de incorporar, de forma explícita y regular, aquellos aspectos de los esquemas sintáctico-semánticos proyectados por los verbos que sean relevantes tanto para clarificar su significado, como para posibilitar al usuario su reutilización.

Es cierto que el diccionario no debe recargarse con informaciones innecesarias para un hablante competente, pero también es cierto que, al menos, el lexicógrafo debe asegurarse de que su obra «contiene toda la información pertinente, sin dejar nada a la intuición del que la emplea» (Garrido Medina, 1992: 197), sin olvidar, además, que la competencia del usuario, a la que se confía buena parte

21 Tampoco hemos encontrado ninguna otra fuente lexicográfica que avale su aceptabilidad. Los sentidos que recoge el Diccionario Histórico, con sus correspondientes ejemplos no nos han servido a este propósito.

22 Por razones de espacio, no hemos transcrito completamente el artículo abrevar. Nos hemos limitado a ofrecer un extracto de las informaciones relacionadas con el tema que nos ocupa. 
del proceso decodificador, dista mucho de ser uniforme (Rey-Debove, 1971).

\section{REFERENCIAS BIBLIOGRÁFICAS:}

AHUMADA LARA, I. (1988): «Información gramatical implícita en la definición lexicográfica», Thesaurus, XLIII, pp. 81-94.

(1989): Aspectos de lexicografía teórica, Granada, Universidad de Granada.

ALVAR EZQUERRA, M. (1993): «Diccionario y gramática», en La lexicografía descriptiva, Barcelona, Biblograf, pp. 87-143.

BÁEZ, V., (1988): Fundamentos críticos de la gramática de dependencias, Madrid, Síntesis.

BOSQUE, I. (1982): «Sobre la teoría de la definición lexicográfica», Verba, 9, pp. $105-123$.

(1989): Las categorías gramaticales, Madrid, Síntesis.

BRESNAN, J. (ed.) (1982): The mental representation of Grammatical Relations, The MIT Press, Cambridge, Massachusetts.

BUSCH, H.J. (1992): «La lexicografía - ¿nada más que remendar calcetines?», en Wotjak (ed.) 1992, pp. 13-37.

CALDERÓN CAMPOS, M. (1994): «Sobre la elaboración de diccionarios monolingües de producción: las definiciones, los ejemplos y las colocaciones léxicas», Foro Hispánico, 6, pp. 105-118.

CANO AGUILAR, R. (1981): Estructuras sintácticas transitivas en el español actual, Madrid, Gredos.

COWIE, A. P. (ed.) (1987): The Dictionary and the Language Learner. Papers from the EURALEX Seminar at the University of Leeds, 1-3 April 1985, Tübingen, Niemeyer.

(1989): «Information on syntactic constructions in the general monolingual dictionary», en Hausmann, 1989.

CUERVO, R.J. (1886-1893): Diccionario de construcción y régimen de la lengua castellana, Bogotá, Instituto Caro y Cuervo, 1953 y 1954.

DEMONTE, V. (1989): Teoría sintáctica: de las estructuras a la rección, Madrid, Síntesis.

Diccionario General Ilustrado de la Lengua española (nueva redacción dir. por M. Alvar Ezquerra), 1987, Barcelona, Biblograf.

DIK, S. (1981): Gramática funcional, Madrid, SGEL.

DUBOIS, J. y CL. DUBOIS (1971): Introduction à la lexicographie: le dictionnaire. Paris, Larousse.

GARRIDO MEDINA, J. (1992): «El léxico en la gramática: hacia una gramática flexible», en Wotjak (ed.), 1992, pp. 190-198.

GRÀCIA I SOLÉ, LL. (1989): La teoria temàtica, Barcelona, Universidad Autónoma de Barcelona. 
GROSS, M. (1981): «Lexocographie et Grammaire», Cahiers de Lexicologie, 39 , pp. 35-46.

HAENSCH, G. y otros (1982): La lexicografía, Madrid, Gredos.

HARTMANN, R.R.K. (1987): «Four perspectives on dictionary use: a critical review of research methods», en Cowie, 1987, pp. 11-28.

HAUSMANN, F.J. y otros (eds.) (1989): Wörterbücher/ Dictionaries/ Dictionnaires, Berlin - New York, Walter de Gruyter.

HERNÁNDEZ, H. (1991): «Sobre el concepto de acepción», Voz y Letra, II, 1, pp. 127-141.

JACKENDOFF, R. (1990): Semantic Structures, The MIT Press, Cambridge, Massachusets.

LEVIN, B. (1991): «Building a Lexicon: The Contribution of Linguistics», International Journal of Lexicography, vol. 4., 3, pp. 205-226.

MARTÍN ZORRAQUINO, M. A. (1979): Las construcciones pronominales en español. Paradigma y desviaciones, Madrid, Gredos.

MOLINER, M. (1966-1967): Diccionario de uso del español, 2 vols. Madrid, Gredos.

MORENO CABRERA, J. C. (1991): Curso universitario de lingüística general

I: Teoría de la gramática y sintaxis general, Madrid, Sintesis.

REAL ACADEMIA ESPAÑOLA (1726-1739): Diccionario de Autoridades, ed. facsímil, Madrid, Gredos, 1963.

(1972): Diccionario histórico, I, a-alá. Madrid.

(1992): Diccionario de la lengua española, Madrid, Gredos.

REY-DEBOVE, J. (1971): Étude linguistique et sémiotique des dictionnaires fraçais contemporains, La Haya-Paris, Mouton.

SCHACK RASMUSSEN, L. (1992): «Los aspectos metalexicográficos de un diccionario semántico», en Wotjak, ed., 1992, pp. 38-62.

SCHROTEN, J. (1992): «Estructura argumental y polisemia» Actas del IV Congreso Internacional de EURALEX, Barcelona, Biblograf, pp. 233-243.

SECO, M. (1978): «Problemas formales de la definición lexicográfica», en Estudios ofrecidos a Emilio Alarcos, Oviedo, pp. 217-241.

(1979): «El 'contorno' en la definición lexicográfica», Homenaje a Samuel Gili Gaya (in Memoriam), Barcelona, pp. 183-191.

VERA LUJÁN, A. (1990): Las construcciones pronominales pasivas e impersonales en español, Murcia, Universidad de Murcia.

VILELA, M. (1992): «A gramatica nos dicionários de lingua: O verbo deixar», Actas del XIX Congreso Internacional de Lingüística y Filología Románicas, II, La Coruña, pp. 111-131.

WERNER, R. (1982): «La definición lexicográfica», en Haensch y otros, 1982, $\mathrm{pp}$.

WOTJAK, G. (1992): Estudios de lexicología y metalexicografía del español actual, Tübingen, Max Niemeyer. 